\title{
Optimization of Constituents of (Ni, MO, Cu)/Kieselguhr Catalyst by Response Surface Methodology for Glycerol Production by Hydrogenolysis of Sucrose
}

\author{
Tanuja Srivastava ${ }^{1}$ \\ Director \\ Bhai Gurdas Institute of Engineering \& Technology, \\ Sangrur (INDIA)
}

\author{
D.C. Saxena \\ Department of Food Technology, \\ Sant Longowal Institute of Engineering and \\ Technology, Longowal (INDIA)
}

\begin{abstract}
Sucrose hydrogenolysis is industrially important for the production of polyols. To provide high glycerol yield under milder reaction conditions, a nickel catalyst promoted by Molybdenum and copper supported on kieselguhr was synthesized and optimized using Response Surface Methodology. A 3X5 experimental design has been adopted to study the effect of these constituents. A linear second-order model has been developed to optimize and to study the interaction effects on glycerol yield in the catalytic hydrogenolysis of sucrose. Increase in nickel loading in the catalyst increased its activity. Increase in Molybdenum also increased the catalyst activity but changed the reaction mechanism as well. Increase in copper caused the direct hydrogenolysis of sucrose instead of its first splitting into monosaccahrides and their subsequent hydrogenolysis. Maximum glycerol yield of $27.79 \%$ was identified at an optimum nickel, Molybdenum and copper concentration of $29.80 \%, 10.0 \%$, and $1.07 \%$, respectively. The optimized catalyst has been characterized by the electron microscopy, Xray diffraction, and magnetic measurement techniques.
\end{abstract}

\section{Keywords: $\quad$ Catalyst, Nickel, Molybdenum, Copper, Response Surface Methodology, Glycerol, Hydrogenolysis, Sucrose}

\section{INTRODUCTION}

Polyalcohols have wide industrial and other usages. Presently, they are being mainly produced from petroleum and its products. Hydrogenolysis of regenerative source as sucrose is an alternate route for polyol production. Catalytic hydrogenolysis of sucrose yields industrially important glycerol, ethylene glycol and propylene glycol. There is a need of a catalyst which provides high product yields under milder reaction conditions. Catalyst preparation procedure affected the final catalyst and enhanced the catalyst activity and selectivity considerably [1,2,3,4]. Li et al. [5] have used Ni-P amorphous alloy catalyst to produce sorbitol by glucose hydrogenation.

Nickel supported on kieselguhr is an effective catalyst for hydrogenolysis. But its activity can be appreciably increased, making it more effective for hydrogenolysis, by doping it with Molybdenum and copper $[6,7,8]$. This high activity results because of increased surface area on doping. Kusuma and Uno [9] found that catalyst prepared from nickel chloride was less reactive than that prepared from nickel nitrate and ascribe the cause to the presence of unreduced chlorides. Watterman and Tusenbroch [10] used nickel sulphate to precipitate nickel on kieselguhr and investigated the effect of heat treatment on the activity of the resulting catalyst. Norman [11] investigated the effect of calcination temperature on the activity of nickel-kieselguhr catalyst in relation to the thermal conditions of precipitation, drying and reduction. The catalyst was prepared by treating a solution of nickel sulphate with that of sodium carbonate. Several workers studied various $\mathrm{Ni}$ catalysts deposited on classical support $\left(\mathrm{SiO}_{2}, \mathrm{Al}_{2} \mathrm{O}_{3}, \mathrm{MgO}\right)[12,13,14,15,16,17,18]$ and on less conventional material (rice husk ash) $[19,20]$. Vogt et al. [6] found that the activity of HNiNa $\gamma$ zeolite decreased with an increase in $\mathrm{H}^{+}$concentrations during hydrogenolysis. Tuslier et al. [7] studied various Ni catalysts deposited on classical support $\left(\mathrm{SiO}_{2}, \mathrm{Al}_{2} \mathrm{O}_{3}, \mathrm{MgO}\right)$ and on less conventional material. Aguinagar et al. [8] investigated the influence of support on the activity and selectivity of supported $\mathrm{Ni}$ catalysts. Activation of supported $\mathrm{Ni}$ catalysts through modification of surfaces of catalyst support has been studied by various workers [22, 23, 24]. Nishiyama [9] studied activation of supported $\mathrm{Ni}$ catalysts through modification of surfaces of catalyst support.

Response surface methodology (RSM) is an effective tool to optimize the process and process variables [10]. An experimental design such as the central composite rotatable design (CCRD) to fit a model by least square technique has been selected during the studies. If the proposed model is adequate, as revealed by the diagnostic checking provided by an analysis of variance (ANOVA), the 3-D plots and contours can be usefully employed to study the response surface and locate the optimum. The basic principle of RSM is to relate product properties of regression equations that describe interrelations between input parameters and product properties. Yeh et al. [26] have used RSM to optimize the surface properties of sol-gel silica. It is apparent from the literature that use of RSM for catalyst synthesis in hydrogenolysis process is rare. Efremov et al. have optimized the composition of multicomponent catalyst for selective reduction of nitrogen oxides [27].

The present work provides studies on the effect of $\mathrm{Ni}, \mathrm{MO}$, and $\mathrm{Cu}$ amounts in the catalyst on glycerol yield of hydrogenolysis of sucrose. It is apparent from the literature that use of RSM for catalyst synthesis in hydrogenolysis process is rare. Therefore, the technique of response surface methodology is used to optimize the amounts of catalyst constituents to maximize yield of glycerol, the most expensive polyol among those obtained during the reaction.

\section{EXPERIMENTAL}

Materials: Kieselguhr was obtained from S.D. Fine Chemicals, Mumbai (India). Analytical grade salts of nickel, Molybdenum, and copper as well as sodium carbonate and ammonium hydroxide were used for catalyst preparation. Laboratory grade sucrose (Qualigens, Mumbai, India) and high purity hydrogen (Modi Gases, New Delhi, India) were used for hydrogenolysis reaction.

\section{Methods}

Catalyst preparation 
Nickel, Molybdenum, and copper were coprecipitated on kieselguhr using a Heidolph rotary vacuum evaporator with electronic temperature agitation and control and incorporating various attachments and fittings. Nickel concentration in the catalyst was varied by changing nickel nitrate and kieselguhr ration, Molybdenum concentration by changing tungstic acid ( $i n$ the presence of ammonium hydroxide) and kiseselguhr ration, and the copper concentration by changing cupric nitrate and kieselguhr ration for catalyst synthesis. The percentage of nickel, copper, and Molybdenum was estimated by standard gravimetric analysis. After digestion of above slurry of nickel, Molybdenum, and copper, sodium carbonate of $10 \%$ concentration was added to the slurry at $80^{\circ} \mathrm{C}$. The slurry was finally digested for 90 minutes at $90^{\circ} \mathrm{C}$. It was thereafter filtered, washed with 2 liters of hot distilled water, and dried under vacuum at $150^{\circ} \mathrm{C}$. The dried green catalyst is ground to pass through a $200-$ mesh sieve.

The catalyst compositions was determined by standard gravimetric analysis. It was activated by reduction in pure hydrogen current $600^{\circ} \mathrm{C}$ for two hours. The reaction was carried out in a microprocessor controlled $450 \mathrm{ml}$ high pressure Parr reactor assembly (USA) under the following conditions:

Catalyst amount: $12.5 \%$ of sucrose weight; Sucrose concentration: $17 \%$ by weight

Temperature: $150^{\circ} \mathrm{C}$; Pressure: $50 \mathrm{~atm}$; Reaction time: $45 \mathrm{~min}$

The technique of thin-layer chromatography coupled with flame ionization detector was used to analyze the products of hydrogenolysis of sucrose. Iatron TH-10 MK IV TLC/FID analyzer was used for this purpose.

\section{Selection of center point of variable range}

The points at which glycerol yields maximum were selected as a center points for each variable range in the experimental design.

\section{Experimental Design:}

Yield of glycerol was the only response (Y) measured in the study. The experimental region extended from -1.682 to +1.682 in terms of the coded independent variables $\mathrm{X}_{\mathrm{i}}$. The coding facilitated the computations for regression analysis and optimum search. The increments of variation for each variable, spaced around the center-point ratios, along with equations relating actual and coded ratios are presented in Table 1. The range of experimental design (actual values) was decided based on the preliminary studies. By substitution in these equations, catalyst compositions were coded for solutions of the multiple - regression (prediction) equations.

A central composite rotatable design (CCRD) was adopted, as shown in Table 2 [31]. This design was specifically suited for analyses with second order polynomials. The CCRD combined the vertices of a hypercube whose coordinates are given by the $2^{\text {n-1 }}$ factorial design (runs 1-8) with the 'star' points (runs 9-14). The star points were added to the factorial design to provide for estimation of curvatures of the model [32]. Six replicate experiments (runs 15-20), at the center of the design, were performed. In earlier studies, co-author randomized the experiments in order to minimize the effects of unexplained variability in the observed responses due to extraneous factors
[33]. A similar approach was implemented in the present study.

For analysis of the experimental design by RSM, it is assumed that ' $n$ ' mathematical functions, $b_{k}(k=1,2,3$, .,n), exist for each of the response variables $Y_{k}$, in terms of ' $\mathrm{m}$ ' independent processing factors, $\mathrm{x}_{\mathrm{i}}(\mathrm{I}=1,2,3, \ldots \ldots \ldots . \mathrm{m})$, such as [34] :

$\mathrm{Y}_{\mathrm{k}}=\mathrm{f}_{\mathrm{k}}\left(\mathrm{x}_{1}, \mathrm{x}_{2}, \ldots \ldots \ldots, \mathrm{x}_{\mathrm{m}}\right)$

In our case, $\mathrm{n}=1 \& \mathrm{~m}=3$

$\mathrm{Y}=$ Glycerol Yield $(\%), \mathrm{x}_{1}=\operatorname{Nickel}(\%), \mathrm{x}_{2}=$ Molybdenum $(\%), \mathrm{x}_{3}=$ Copper $(\%)$

The unknown functions, $f_{k}$, was assumed to be represented approximately by a second degree polynomial equation:

$\mathrm{Y}_{\mathrm{k}}=\mathrm{b}_{\mathrm{k} 0}+\sum_{\mathrm{i}=1}^{3} \mathrm{~b}_{\mathrm{ki}} \mathrm{X}_{\mathrm{i}}+\sum_{\mathrm{i}=1}^{3} \mathrm{~b}_{\mathrm{kii}} \mathrm{X}_{\mathrm{i}}^{2}+\sum_{\mathrm{i} \neq \mathrm{j}=1}^{3} \mathrm{~b}_{\mathrm{kij}} \mathrm{X}_{\mathrm{i}} \mathrm{X}_{\mathrm{j}}$

where $b_{\mathrm{ko}}$ is the value of the fitted response at the center point of the design i.e. $(0,0,0), b_{k i}, b_{k i i}, \& b_{k i j}$ are the linear, quadratic and cross-product regression terms, respectively.

\section{Analysis of Data}

The regression analysis for fitting the model represented by Equation $\mathbf{2}$ to experimental data and maximization of the polynomial thus fitted was performed by numerical techniques using the mathematical Optimizer procedure of the Quattro Pro Software package (Quattro Pro for windows Ver. 5.0) that deals with constraints. The mapping of the fitted response surfaces was achieved using a surfer program (Surfer Access System, Version 3.0, 1987 Golden Software Inc., Golden Co., USA). The response surfaces and the corresponding contour plots for this model were plotted as a function of two variables, while keeping the other variable at an optimum value.

\section{Characterization of the optimized catalyst}

Physicochemical properties of the catalyst were studied using techniques of electron microscopy, X-ray diffraction, and magnetic measurements under following conditions:

a) Electron Microscopy: The activated catalyst was powdered and suspended in double distilled water. The suspension was allowed to settle for about an hour. A drop from the suspension was carefully placed on 200-mesh carbon coated copper grids. After drying, the grid was examined under a JEOL GEM 2000 FX transmission electron microscope having a resolution $1.5 \mathrm{~A}^{\circ}$ and operating at $120 \mathrm{KV}$. Gold diffraction pattern was used as a standard for interpreting the diffraction patterns.

b) X-ray diffraction technique: The finely powdered samples of catalyst were mounted individually on SEIFERT (JSO DEBYE FLEX 2002) X-ray generator. The $X$-ray data were recorded at a scanning speed of $1.2^{\circ}$ per minute $(2 \varphi)$ between $\varphi=$ $10^{\circ}$ and $62^{\circ}$. The monochromatic beam of $\mathrm{Cuk}_{\alpha}$ radiation was used. The diffractometer was operated at a count rate of 5K CPM and a time constant of 10 sec. The scanning slit was fixed at $2 \mathrm{~mm}$ and the receiving slit at $0.3 \mathrm{~mm}$. The X-ray tube was driven at $30 \mathrm{KV}$ and $20 \mathrm{~mA}$. Diffracted intensities were 
measured by means of a scintillating column at a chart speed of $30 \mathrm{~mm} / \mathrm{min}$. The correction for instrumental breadth of diffraction peak under identical conditions was evaluated using standard aluminum samples annealed for 4 hours at $300^{\circ} \mathrm{C}$.

c) Magnetic measurements: Finally powdered catalyst samples were pressed in cylindrical pellets (3 $\mathrm{mm}$ diameter and $3 \mathrm{~mm}$ height) in inert atmosphere to avoid oxidation. A polymer coating was applied to the surface in order to impart mechanical strength to the pellets and to prevent further oxidation of the reduced catalyst. The measurements were carried out at room temperature using a Varian V-7200 series 9-inch electromagnet and a parallel field vibrating samples magnetometer (Model 150 A PARC, USA).

\section{Experimental Procedure}

As per the experimental design, nickel, Molybdenum, and copper were co-precipitated on kieselguhr using a Heidolph rotary vacuum evaporator with electronic temperature agitation and control and incorporating various attachments and fittings. Nickel concentration in the catalyst was varied by changing nickel nitrate and kieselguhr ratio, Molybdenum concentration by changing tungstic acid and kieselguhr ratio, and the copper concentration by changing cupric nitrate and kieselguhr ratio for catalyst synthesis.

The reaction was carried out in a microprocessor controlled $450 \mathrm{ml}$ high pressure Parr reactor assembly (USA) under the following conditions:

Catalyst amount: $12.5 \%$ of sucrose weight; Sucrose concentration: $17 \%$ by weight

Temperature: $150^{\circ} \mathrm{C}$; Pressure: 50 atm.; Reaction time: $45 \mathrm{~min}$.

The technique of thin-layer chromatography coupled with flame ionization detector was used to analyze the products of hydrogenolysis of sucrose. Iatron TH-10 MK IV TLCIFID analyzer was used for this purpose.

\section{RESULTS AND DISCUSSION}

\section{Effect of catalyst's nickel loading}

Fig.1 shows changes in catalyst nickel loading with change in nickel nitrate/kieselguhr ration and simultaneously the effect of nickel loading on glycerol yield. The nickel percentage rises linearly in the beginning but tapers off later because of the limiting presence of sodium carbonate used for precipitation. The amount of sodium carbonate has not been changed with changing nickel nitrate/kieselguhr ration. Sucrose hydrogenolysis was carried out using six catalyst samples with nickel wt. \% changing from 8.4 to 42.1 .

During catalyst synthesis nickel is deposited in the pores of kieselguhr. Initially not all kieselguhr surfaces ar coated with nickel particles. This coating hence catalyst nickel surface area increases with increase in the catalyst's nickel loading. The catalyst activity also increases with the nickel surface area there by increasing sucrose conversion. When the entire kieselguhr surface is covered with nickel, any further increase in its loading tend to deposit nickel on nickel itself. This fills up the kieselhuhr pores. High surface area of the catalyst is because of porous nature of the support, when pores are filled the surface area decreases consequently decreasing the catalyst activity and hence the sucrose conversion.

In the nickel loading range investigated, nickel particle size in the catalyst remained constant and was not a cause for changing catalyst activity. This is revealed in Fig.2 by constant peak widths at half height of (111) nickel diffraction peak obtained with different nickel loading in the catalyst. The peak width at half peak height is known to be inversely proportional to the particle size. The maximum glycerol yield is attained at 30.9 wt. \% of nickel corresponding to nickel nitrate/ kiteselguhr ratio of 2.65 and therefore, the center point was taken as 30.0 weight percentage.

\section{Effect of catalyst's tungsten loading}

Tungsten loading in the catalyst was varied by changing tungstic acid and kieselguhr ratio during synthesis. Fig. 3 shows the variation in tungsten loading with tungstic acid/kieselhuhr ratio. The relation is found to be linear initially then tapers down slightly beyond the ration of about 0.32 . Catalyst samples were made by varying tungsten loading from 1.21 to $12.14 \%$ by weight and the sucrose hydrogenolysis was carried out with these samples to observe the influence of the catalyst's tungsten loading on the product distribution as shown in same figure Glycerol yield is the maximum at $9.8 \%$ tungsten loading that corresponds to tungsten acid/kieselguhr ratio of 0.336 and therefore, the center point for tungsten was taken as $10.0 \mathrm{wt} . \%$.

\section{Effect of catalyst's copper loading}

Copper loading in the catalyst was varied from 0.5 to $2 \%$ of the catalyst weight by changing cupric nitrate and kieselhuhr ratio during the synthesis as shown in Fig.4 which shows linear variation of copper loading with change in cupric nitrate/kieselhuhr ratio. As copper compound was precipitated on the catalyst using an excess of sodium carbonate this linear relationship is expected. As also shown the influence of copper loading on product distribution in the same figure, the yield of glycerol was the maximum at copper loading of $1.05 \%$ which corresponds to cupric nitrate/kieselguhr ratio of 0.0975 and therefore, the center point for copper loading was taken as 1.0 weight percentage.

\section{Diagnostic Checking of the Fitted Model}

Regression analysis for the model indicated that the fitted quadratic model accounted for $93.1 \%$ of the variations in the experimental data, which was highly significant. A multiple regression equation was generated relating the percentage yield of glycerol to coded levels of the variables.

The model was developed as follows:

Glycerol

(Y) $=27.76-0.23 X_{1}+0.39 X_{3}-2.20 X_{1}^{2}-2.09 X_{2}^{2}-1.46 X_{3}^{2}+0.44 X_{1} X_{3} \ldots$ (3)

All main effects, linear and quadratic, and interaction of effects were calculated for the model. The estimated effects were used to plot a standardized Pareto chart for the model (Fig. 5); the chart consists of bars with lengths proportional to the absolute values of the estimated effects divided by their standard errors. The chart includes a vertical line at the critical $t-$ value for a $95 \%$ confidence level. A bar crossing this vertical line corresponds to a factor or combination of factors that has a significant effect in the response. 
The regression coefficients are shown in Table 3, as well as the correlation coefficient obtained for the model. The correlation coefficient for glycerol yield $\left(\mathrm{R}^{2}=0.931\right)$ is quite high for a response surface. The concentration of nickel in the catalyst had negative linear effect significant only at $95 \%$ level and a highly significant negative quadratic effect on glycerol yield at $99.9 \%$ level. Molybdenum had highly negative quadratic effect. On the other hand, the copper concentration had positive linear effect (significant at 95\% level) but highly significant negative effect on glycerol yield. The interaction of nickel and copper had a significant positive effect on glycerol yield. However, the interaction of nickel with copper and that of Molybdenum with copper showed no significant effects on the glycerol yield.

\section{Analysis of variance}

When a model has been selected, an Analysis of Variance is calculated to assess how well the model represents the data. An Analysis of Variance for the response is presented in Table 4. To evaluate the goodness of the model, the Coefficient of Variation (the ratio of the standard error of estimate to the mean value expressed as a percentage) and Fvalue tests are conducted. As a general rule, the Coefficient of Variation should be not greater than $10 \%$ [12]. In our case, the coefficient of variation for glycerol yield was $4.32 \%$. Also, the F-value for response was significant even at $99 \%$ whereas lack of fit was not significant at $99 \%$ level. On the basis of Analysis of Variance, the conclusion is that the selected model adequately represents the data for glycerol yield.

A diagnostic plot for the response is shown in Fig. 6. From analysis of residuals it is possible to conclude that they are randomly distributed around zero and there is no evidence of outliers (no point lying away from the mean more than four times the standard deviation).

\section{Conditions for optimum responses}

Models were useful in indicating the direction in which to change variables in order to maximize glycerol yield. The optimum conditions to yield maximum glycerol are presented in Table 5. The model provides the information about the influence of each variable on the glycerol yield in the catalytic hydrogenolysis of sucrose. However, these are the optimized conditions that provide the information to produce maximum yields of glycerol.

Optimum values of glycerol yield for all variables lie exactly in the middle of the experimental range, indicating the validity of the selection of the variables range. The response surfaces in Figures $\mathbf{7}$ to $\mathbf{9}$ and the corresponding contour plots in Figures 7 - 9 are based on the above model (Y), keeping one variable constant at the optimum level and varying the other two within the experimental range.

The surface plot of glycerol yield as a function of nickel and Molybdenum demonstrated the maximum yield at an optimum nickel concentration of $29.80 \%$ and Molybdenum concentration of $10.0 \%$ (Fig. 7). Increasing or decreasing of concentration of any constituents at the optimum concentration resulted in decreased yield. This behaviour may be attributed to the change in catalytic activity because of change in the catalyst's nickel surface area with increase in the catalyst's nickel loading. During catalyst synthesis, nickel is deposited in the pores of kieselguhr. Initially not all the kieselguhr surface is coated with nickel particles. This coating, hence catalyst's nickel surface area, increases with increase in the catalyst's nickel loading. The catalyst activity also increases with the nickel surface area, thereby increasing sucrose conversion. When the entire kieselguhr surface is covered with nickel, any further increase in its loading tends to deposit nickel on nickel itself. This fills up the kieselguhr pores, resulting in the decreased surface area and thereby decreasing the catalyst activity as well as the sucrose conversion.

As is clear by the X-ray diffraction patterns in Fig. 3, the entire kieselguhr surface was coated with nickel when its loading was between 24.8 and $29.8 \%$ by weight as indicated by decreased peak height of $\alpha$-cristobalite silica upto $29.8 \%$ nickel, and then it became constant. It is known that nickel nitrate reacts with silica during precipitation to form nickel hydrosilicates, thus decreasing the silica amount and its $\mathrm{X}$-ray diffraction peak height [35].

The yield of glycerol attained a maximum at $10.0 \%$ Molybdenum loading. Uncovered sucrose amount decreased continuously with increasing Molybdenum percentage in the catalyst, indicating increased catalyst activity with the Molybdenum amount. This increase may be due to better dispersion of nickel particles resulting from prevention of their coalescence by Molybdenum particles and may also be due to the promotional effect of Molybdenum as a result of electron transfer [36]. It appears that, as Molybdenum loading was increased up to its optimum value of $10.0 \%$, direct hydrogenolysis of sucrose at its fructose units to yield polyols changed to direct hydrogenolysis of both of its glucose and fructose unit, producing the maximum amount of glycerol and glycol.

This may imply maximum dispersion of nickel particles at $10.0 \%$ Molybdenum loading, resulting in a higher catalyst activity. Consequently more of desired polyols were produced. Further, increase in the Molybdenum loading probably made it behave as an active catalyst metal itself, apart from promoting nickel through electron transfer or by dispersing it [6]. As a result, a change in mechanism occurred. Even though catalyst activity was further increased, converting more of sucrose, glycerol and glycol yields declined and high amounts of sorbitol and some unidentified products were formed.

However, as shown in Fig. 8, for high concentration of copper the glycerol yield increases with increasing nickel concentration up to a certain level, whereas for lower copper concentration the pattern follows a parabolic path showing that increasing or decreasing the copper concentration beyond the optimum level resulted in reduced glycerol yield. The same effect can also be seen in Equation 3, which has a highly significant interaction term of nickel and copper concentration. Copper loading in the catalyst was varied from 0.159 to $1.841 \%$ of the catalyst weight by changing cupric nitrate and kieselguhr ratio during the synthesis. The yield of glycerol was maximum at copper loading of $1.07 \%$. Copper loadings beyond optimum decreased sucrose conversion slightly but strongly reduced conversion of glucose, fructose and sorbitol. The fructose conversion was affected to a lesser extent.

The similar effects were observed in the case of response (glycerol yield) as a function of Molybdenum and copper concentration (Fig. 9). It can be inferred that direct hydrogenolysis of sucrose, instead of its first splitting into monosaccharides, was caused by increase in the copper amount.

The catalyst with optimum loading has been synthesized using the method of coprecipitation as described 
above. With the optimum constituent's loading, the hydrogenolysis of sucrose gave glycerol yield of $27.62 \%$, which was almost near to the maximum yield obtained by the optimization procedure. The physicochemical properties of the catalyst studied by various techniques are as follows:

A) Electron Microscopy: The scanning electron micrograph of kieselguhr particles is shown in Fig.11a. the round sharp edged particles have broad size distribution with larger fraction of smaller particles above or below $5 \mu \mathrm{M}$. The transmission electron micrograph shown in Fig. 11b reveals the presence of sharp of sharp edged, round intermingled kieselguhr particles. The electron diffraction obtained from the same region is shown in Fig.11c. Interplanar spacing corresponding to this pattern match with those obtained from X-ray diffraction peaks of the same material. Corecipitaion of the catalyst seems to change the morphology of support particles from sharp edged particles into fibrous state. Fig.11d shows an electron diffraction pattern of gold used as standard for the electron diffraction studies.

B) X-ray diffraction pattern: Fig. 12 shows that $\mathrm{Ni}$ (111) diffraction peak much reduced in intensity and width I case of spent catalyst in comparison to that of freshly reduced on. Except (101) peak of $\alpha$-cristobalite silica, all kieselhuhr peaks also disappeared. This indicates chemicalstructural degradation of the support to some amorphous state and conversion of metallic nickel into some non-metallic amorphous material probably nickel hydroside.

C) Magnetic measurements: The magnetization curves for standard Ni, Ni/Kieselguhr catalyst, $(\mathrm{Ni}, \mathrm{MO}, \mathrm{Cu}) / \mathrm{Kieselguhr}$ catalyst and spent $(\mathrm{Ni}, \mathrm{MO}$, $\mathrm{Cu} /$ Kieselguhr) catalyst are shown in ( $\mathrm{Ni}$, MO, $\mathrm{Cu} / \mathrm{Kieselguhr}$ ) catalyst. However, isolated particles smaller than this size should normally not exhibit saturation at room temperature. The saturation in the present case, therefore, appears to be due to nickel particles lying very close as a result high nickel loading.

\section{CONCLUSION}

It may be concluded that the system of yield of glycerol from catalytic hydrogenolysis of sucrose can effectively be optimized using response surface methodology with a minimum number of experiments. Computerized computations, model building and generation of threedimensional graphs will go a long way to unraveling the complexity of the preparation of catalyst for glycerol production with the different variables used. Nickel, Molybdenum and copper supported on kieselguhr in the concentration of $29.8 \%, 10.0 \%$, and $1.07 \%$, respectively, have been found to yield maximum glycerol concentrations of $27.79 \%$, the most expensive polyol produced by the reaction. The work presented here paves the way to synthesize a commercial catalyst to produce various polyols, particularly glycerol, by hydrogenolysis of sucrose.

\section{ACKNOWLEDGEMENTS}

The authors wish to acknowledge the financial support given by the Department of Science and Technology, New Delhi (Govt. of India), to carry out these studies.

\section{REFERENCES}

[1] V. Ponec., Catal. Rev. - Sci. Eng., 18 (1978), p. 151.
[2] M.E. Dry, Catalysis - Science and Technology, Anderson J.R., Boudart M. Springer-Verlag, New York, (1981), p. 160.

[3] R.J. Madon, E. Iglesia, S.C. Reyes, Selectivity in Catalysis, Suib S.L., Davis M. E.American Chemical Society, Washington, DC, (1993), p. 382 $-396$.

[4] Tanuja Srivastava, Ph.D. Thesis. Kanpur University, Kanpur, India (1996).

[5] H.Li, W. Wang, J.F. Deng, J. Catal. 1(2000), 257 260.

[6] B.N. Kuznetsov, I.A. Ovsyannikova, S.B. Erenbury, A.B. Gilvary, Y.I. Ermakov, Kinetic Katal, (1978), p. $749-753$.

[7] R.A van Santen, M. Neurock, Catal. Rev. - Sci. Eng., 37 (1995), p. 557.

[8] T.Kusuma, Y. Uno, Bull. Phy. Chem. Research Japan 461 (1929), p. 38.

[9] J. Bracicki, T. Borviccki, A. Deion, F. Ryszard, Chem. Abstr. 106 (1985) 28903 t.

[10] J. Wattermann, P. Tussenbrdi, J. Am. Chem. Soc. 60 (1938), p.1501.

[11] W.Norman, J. Am. Chem. Soc. 56 (1942), p.1804.

[12] P. Tuslier, N. Pralind, P. Moral, G.A. Martin, J.A. Dalmov, Inst. Res. Catal. Univ. Cloude, Bernard. 104, 75828a. (1988).

[13] L.S. Glebov, G.A. Kligr, Russ. Chem. Rev., 63 (1994), p.185.

[14] T. Kabea, Y. Aoyama, D. Wang, A. Ishihara, W. Qian, M. Hosoya, Q. Zhang, Appl. Catal. A 209 (2001), 237-247.

[15] C.Kordulisa, A.A. Lappas,C.Fountzoula, K. Drakaki, A. Lycourghiotis, I.A. Vasalos, Appl Catal. A 209 (2001),85-95.

[16] M. Arai, Y. Ikushima, Y. Nishiyama, Bull.Chem. Soc. Jpn. 59 (1986), 347-350.

[17] Z. Sarbak, Appl. Catal. A 207 (2001), 309-314

[18] B. Pawelec, R. Mariscal, J.L.G. Fierro, A Greenwood, P.T. Vasudevan, Appl. Catal. A 206(2001), 295-307.

[19] F.W. Chang, M.T. Tsay,S.P. Liang, Appl. Catal. A209(2001),217-227.

[20] M.T.Tsay, F.W. Chang, Appl. Catal. A 203(2000), $15-22$.

[21] A. Aguinnagr, J.C. Dela Col, J.N. Ausa, M. Montes. 111, 156370. (1989)

[22] Y. Nishiyama, A. Nasahiko (Inst. for Chemical Reaction Science) Tohokeu University, Sendai. 37 (5) (1994), 461-70.

[23] D.C. Sherrington, Supported Reagents and Catalysts in Chemistry,Hodnett B.K., Kybett A.P., Clark J.H. Smith K. Royal Society of Chemistry, Cambridge,(1998), p. 220.

[24] S. Luia, L. Xua, S. Xie, Q. Wanga, G. Xiong, Appl. Catal. A 211(2001) 145-152.

[25] J.S. Hunter, Industrial Quality Control, 15, (1959), p.6.

[26] T.S. Yeh, T.W. Chung, T.C.K. Yang. Use of Response Surface Methodology for the Optimum of Surface Properties of the Sol-gel-Silica, Proceedings of The $17^{\text {th }}$ R.O.C. Symposium of Catalysis and Reaction Engineering (May, 1999)

V.N. Efremov, M.M. Moiseev, V.T. Leonov, V.S. Beskov, V.S.Sobolevskii, J. Appl. Chem. 71 (1998), 442-446.

[28] J.Vela, L. Membrado, V.L. Cebolla, A.C. Ferrando, J. Chorm, Sci., 36, (1998), pp. 479-486. 
[29] V.L. Cebolla, J. Vela, L. Membrado, A.C. Ferrando, J. Chrom, Sci., 36, (1998), pp. 487-494.

[30] T.Bhaskar, K.R. Reddy, C.P. Kumar, M.R.V.S. Murthy, K.V.R. Charya, Appl. Catal. A 211 (2001) 189-201.

[31] W.G. Cochran, G.M. Cox, Experimental Designs (R.A. Bradley, D.G. Kendall, J.S. Hunter \& G.S. Watson, Eds.), 2nd edn., John Wiley and Sons, New York, 1957, p. 335.

[32] A.M. Joglekar, D.T. May, Product excellence through design of experiments, Cereal Foods World, 32, (1987), p.857.

[33] D.C. Saxena, P.H. Rao, Optimization of ingredients and process conditions for the preparation of tandoori roti using response surface methodology, Int. J. Food Sci. Technol., 31, (1996), p.345.

[34] J.D. Floros, M.S. Chinnan, Optimization of pimiento pepper lye-peeling process using response surface methodology, Transaction of the American Society of Agriculture Engineers, 30, (1987), p.560.

[35] J.E. Ritsko (GTE, Sylvania. Inc.) U.S. 39, 56,474 (cl. 423-593), (01641100) 11 May 1976, Appl. $544058,27^{\text {th }}$ Jan., 1975, 3.

Table 1. Values of Coded Levels and Equations Relating Actual $x_{i}$ and Coded $X_{i}$ Ratios

\begin{tabular}{|c|c|c|c|c|c|c|c|c|}
\hline \multirow{2}{*}{$\begin{array}{l}\text { Independent } \\
\text { Variables }\end{array}$} & \multirow[t]{2}{*}{ Unit } & \multicolumn{2}{|c|}{ Symbols } & \multicolumn{5}{|l|}{ Levels } \\
\hline & & Coded & Actual & -1.682 & -1 & $\mathbf{0}$ & +1 & +1.682 \\
\hline Nickel & $\%$ & $X_{1}$ & $\mathrm{x}_{1}$ & 21.59 & 25.0 & 30.0 & 35.0 & 38.41 \\
\hline Molybdenum & $\%$ & $\mathrm{X}_{2}$ & $\mathrm{x}_{2}$ & 4.954 & 7.0 & 10.0 & 13.0 & 15.046 \\
\hline Copper & $\%$ & $\mathrm{X}_{3}$ & $\mathrm{x}_{3}$ & 0.159 & 0.5 & 1.0 & 1.5 & 1.841 \\
\hline
\end{tabular}

Where $\quad \mathrm{X}_{1}=\left(\mathrm{x}_{1}-30\right) / 5 ; \quad \mathrm{X}_{2}=\left(\mathrm{x}_{2}-10\right) / 3 ; \quad \mathrm{X}_{3}=\left(\mathrm{x}_{3}-1.0\right) / 0.5$ 
Table 2. Central composite design arrangement and response

\begin{tabular}{|c|c|c|c|c|}
\hline \multirow{2}{*}{$\begin{array}{l}\text { Experiment } \\
\text { No. }\end{array}$} & \multicolumn{3}{|c|}{ Variable Levels } & \multirow{2}{*}{$\begin{array}{l}\text { Response } \\
\text { Yield (\%) }\end{array}$} \\
\hline & $\mathbf{X}_{1}$ & $\mathbf{X}_{2}$ & $\mathbf{X}_{3}$ & \\
\hline 1 & -1.00 & -1.00 & -1.00 & 21.98 \\
\hline 2 & 1.00 & -1.00 & -1.00 & 20.91 \\
\hline 3 & -1.00 & 1.00 & -1.00 & 22.23 \\
\hline 4 & 1.00 & 1.00 & -1.00 & 19.51 \\
\hline 5 & -1.00 & -1.00 & 1.00 & 21.95 \\
\hline 6 & 1.00 & -1.00 & 1.00 & 21.41 \\
\hline 7 & -1.00 & 1.00 & 1.00 & 21.58 \\
\hline 8 & 1.00 & 1.00 & 1.00 & 21.81 \\
\hline 9 & -1.682 & 0.00 & 0.00 & 22.11 \\
\hline 10 & 1.682 & 0.00 & 0.00 & 22.64 \\
\hline 11 & 0.00 & -1.682 & 0.00 & 22.47 \\
\hline 12 & 0.00 & 1.682 & 0.00 & 22.87 \\
\hline 13 & 0.00 & 0.00 & -1.682 & 23.52 \\
\hline 14 & 0.00 & 0.00 & 1.682 & 25.41 \\
\hline 15 & 0.00 & 0.00 & 0.00 & 27.69 \\
\hline 16 & 0.00 & 0.00 & 0.00 & 28.12 \\
\hline 17 & 0.00 & 0.00 & 0.00 & 26.98 \\
\hline 18 & 0.00 & 0.00 & 0.00 & 27.88 \\
\hline 19 & 0.00 & 0.00 & 0.00 & 28.06 \\
\hline 20 & 0.00 & 0.00 & 0.00 & 27.56 \\
\hline
\end{tabular}

Table 3. Estimated Coefficients of the Fitted Quadratic Equation for the Response based on t-statistic 


\begin{tabular}{|c|c|c|}
\hline Coefficients & Estimated coefficients & t-statistic \\
\hline $\mathbf{X}_{\mathbf{0}}$ & 27.76 & 66.37 \\
\hline$X_{1}$ & $-0.23 *$ & 0.85 \\
\hline $\mathbf{X}_{2}$ & -0.03 & 0.12 \\
\hline $\mathbf{X}_{3}$ & $0.39 *$ & 1.40 \\
\hline $\mathrm{X}_{1}^{2}$ & $-2.20 * * *$ & 8.14 \\
\hline $\mathbf{X}_{2}^{2}$ & $-2.09 * * *$ & 7.75 \\
\hline $\mathbf{X}_{3}^{2}$ & $-1.46^{* * * *}$ & 5.40 \\
\hline$X_{12}$ & -0.11 & 0.30 \\
\hline $\mathbf{X}_{13}$ & $0.44 *$ & 1.20 \\
\hline $\mathbf{X}_{23}$ & 0.15 & 0.41 \\
\hline
\end{tabular}

$$
\mathbf{R}^{2}=0.931 ; \quad \text { Degrees of freedom }=9
$$

$* \mathbf{P}<0.5(0.703) ; * * \mathbf{P}<0.05(2.262) ; * * * \mathrm{P}<0.01$ (3.250); Table 4. Analysis of Variance for the Model

Table 4. Analysis of Variance for the Model

\begin{tabular}{|c|c|c|c|c|c|c|c|}
\hline Response & $\begin{array}{l}\text { Sources } \\
\text { Variation }\end{array}$ & of & $\begin{array}{l}\text { Degree } \\
\text { freedom }\end{array}$ & of & Sum of Squares & Mean Square & $\mathbf{F}$ \\
\hline \multirow{5}{*}{$\mathbf{Y}$} & Regression & & 9 & & 142.36 & 15.82 & $15.04 * *$ \\
\hline & Residual & & 10 & & 10.52 & 1.05 & \\
\hline & Lack of Fit & & 5 & & 9.645 & 1.608 & $9.184^{*}$ \\
\hline & Pure Error & & 5 & & 0.875 & 0.175 & \\
\hline & Total & & 19 & & 152.88 & & \\
\hline
\end{tabular}

$* \mathbf{P}<0.05(9,10)=3.02 ; * * \mathbf{P}<0.01(9,10)=4.95$

$* \mathbf{P}<0.05(5,5)=5.05 ; * * \mathbf{P}<0.01(5,5)=10.97$

Table 5. Optimum Conditions for Percentage Yield of Glycerol

\begin{tabular}{lll}
\hline Variables & Coded Values & Actual Values \\
\hline Nickel $(\%)$ & -0.04 & 29.80
\end{tabular}




\section{FIGURE CAPTIONS:}

Figure 1. Effect of Nickel Nitrate/ Kieselguhr ratio on Nickel percentage and Glycerol yield Figure 2. Eggect of Nickel percentage on (111) Nickel peak in X-ray diffraction patterns of activated catalyst Figure 3. Effect of Tungstic acid/ Kieselguhr ratio on Tungsten percentage and Glycerol yield Figure 4. Effect of Cupric Nitrate/ Kieselhuhr ratio on Copper percentage and Glycerol yield Figure 5. Standard Pareto chart for the estimated effects of the model.

Figure 6. Standard residuals between experimental values and values predicted by the surface response model vs. model values.

Figure 7. Effect of Nickel and Tungsten concentration in the catalyst on Glycerol production Figure 8. Effect of Nickel and Copper concentration in the catalyst on Glycerol production.

Figure 9. Effect of Tungsten and Copper concentration in the catalyst on Glycerol production.

Figure 10. Effect of Ni percentage on kieselguhr peaks at 11.063 in $\mathrm{X}$-ray diffraction patterns of activated $(\mathrm{Ni}, \mathrm{W}, \mathrm{Cu}) /$ kieselguhr catalyst.

Figure 11a. Scanning electron micrograph of Kieselguhr particles

Figure 11b. Transmission electron micrograph of Kieselguhr particles

Figure 11c. Electron diffraction pattern of gold film

Figure 12. Nickel (111) peaks in X-ray diffraction patterns of activated and spent catalysts

Figure 13. Effect of applied magnetic field on magnetic moments

\section{LEGENDS FOR THE FIGURES}

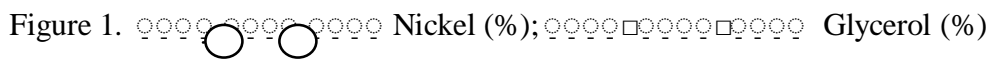

Figure 2. Peak No.

$\begin{array}{ll}1 & 24.2 \\ 2 & 31.4 \\ 3 & 37.3 \\ 4 & 42.1\end{array}$

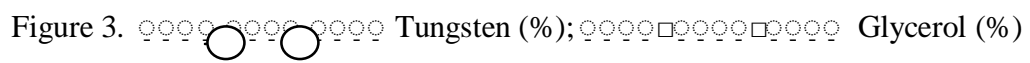

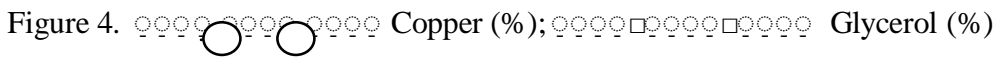

Figure 5. $\mathbf{t}+\mathbb{\&} \&$ values for the coefficients in the model

Figure 6. $\sigma$ Standard deviation

Figure 10. Peak No. \% Nickel in the catalyst

$\begin{array}{ll}1 & 24.8 \\ 2 & 29.8\end{array}$


3

4

Figure 12. $\quad 1$ - Activated catalyst;
34.8

38.4

Figure 13. $9909 \bigcirc 999$ Standard Nickel; $999 \square 999 \square 999$ Spent catalyst

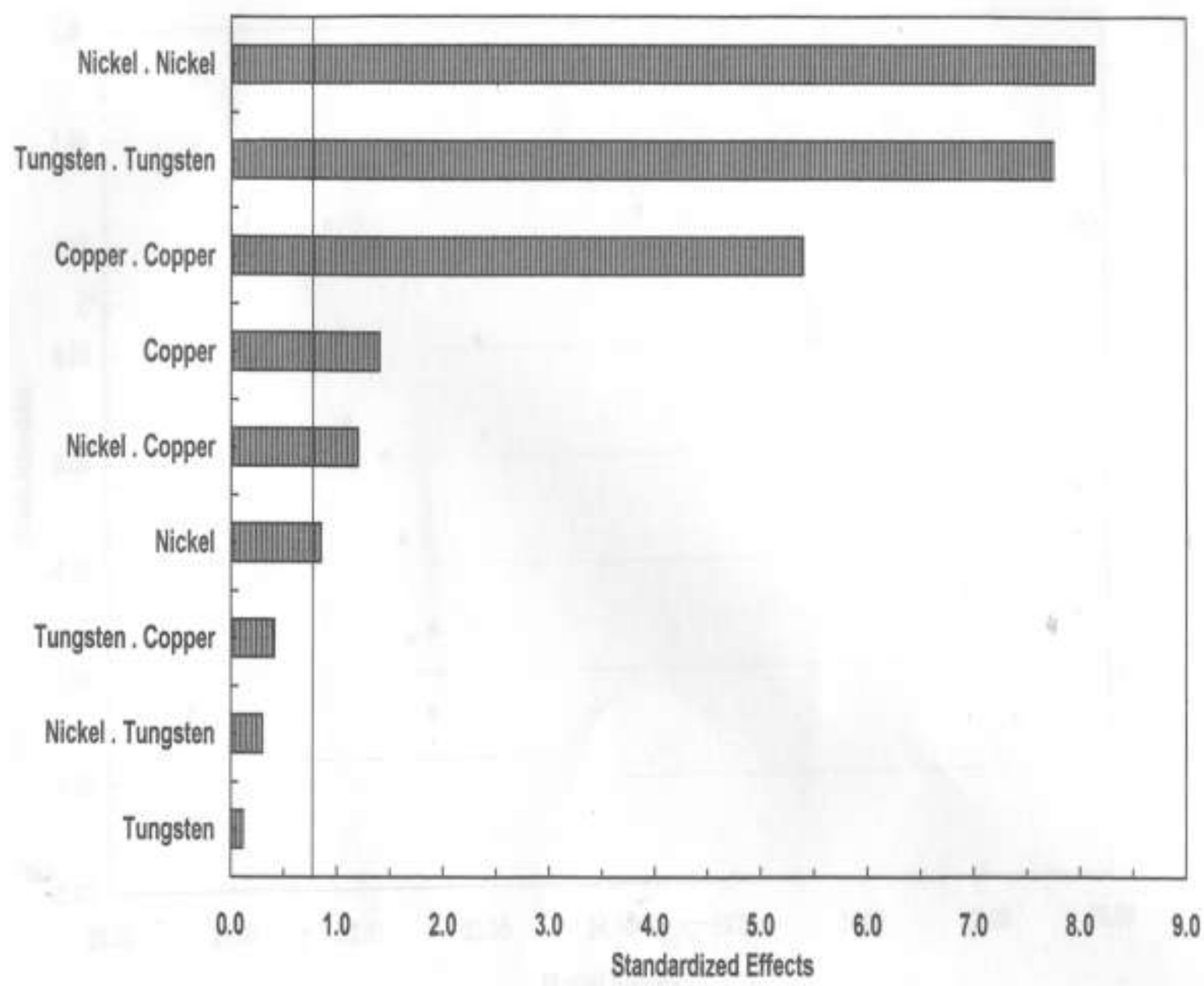

Figure.1 

Volume 2 No. 3, June, 2012

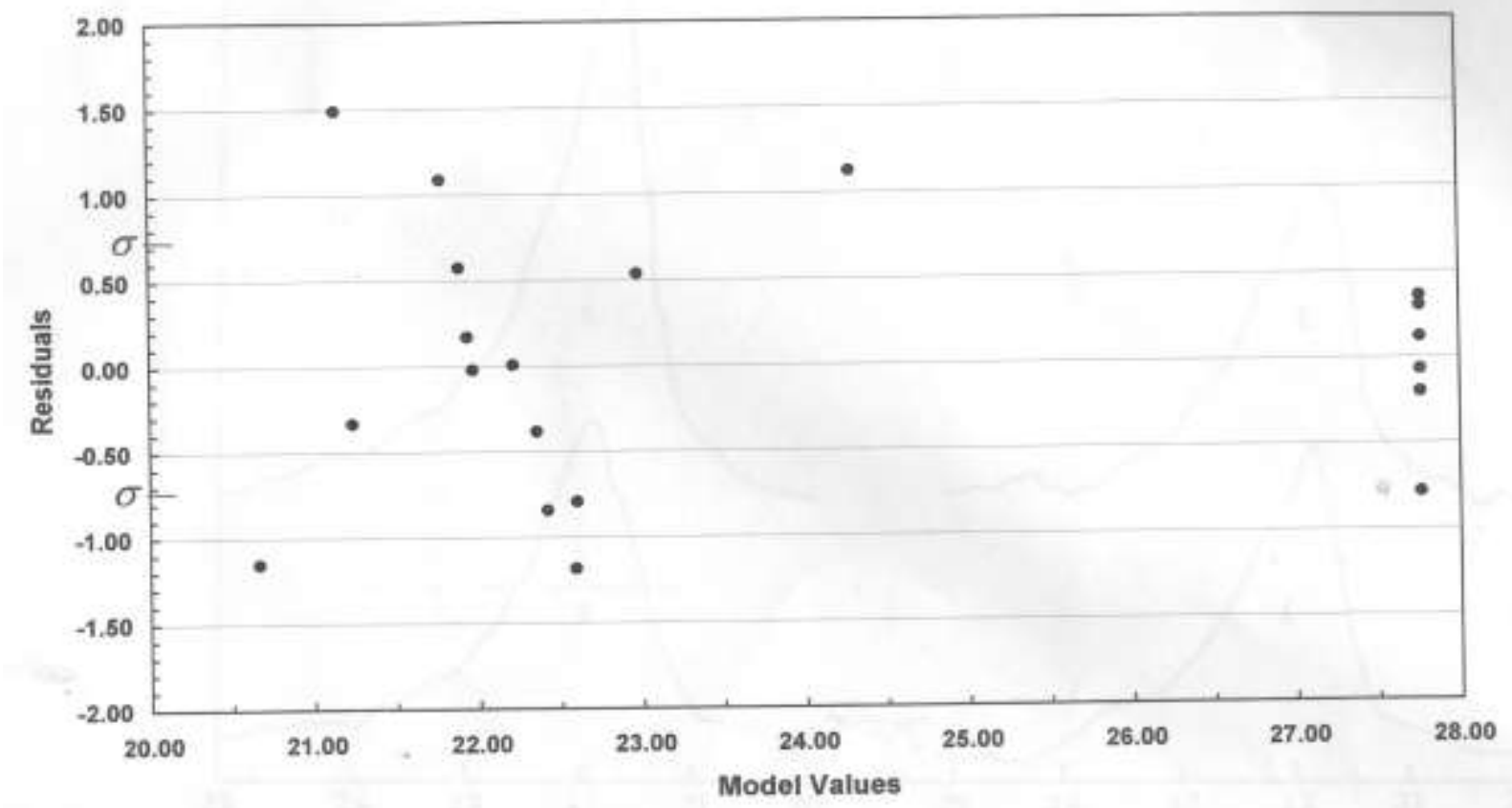

Figure.2

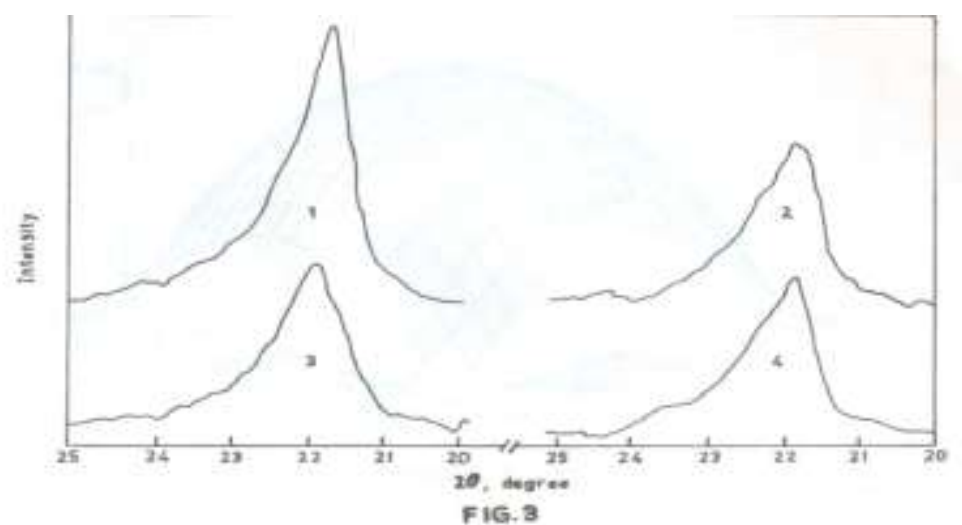




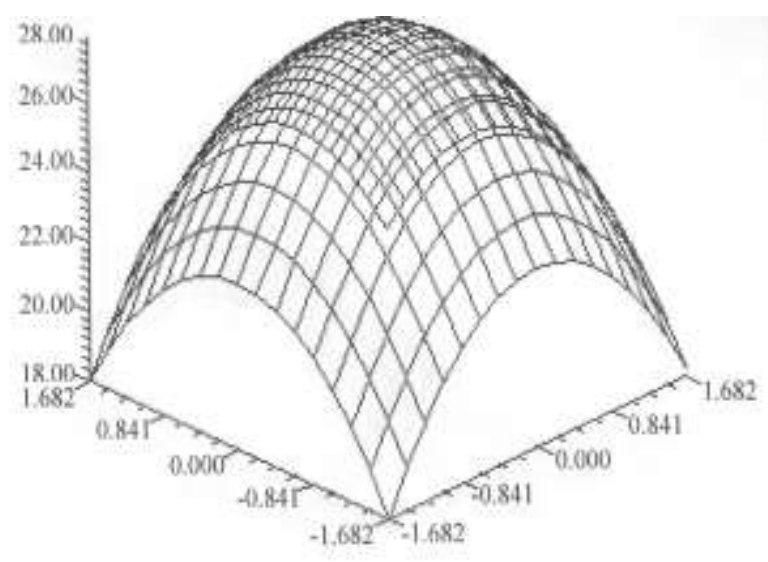

Figure 4.

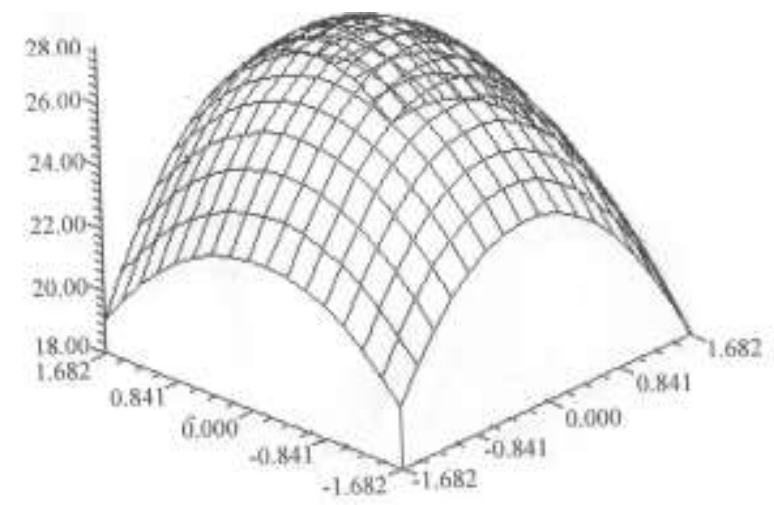

Figure 5. 


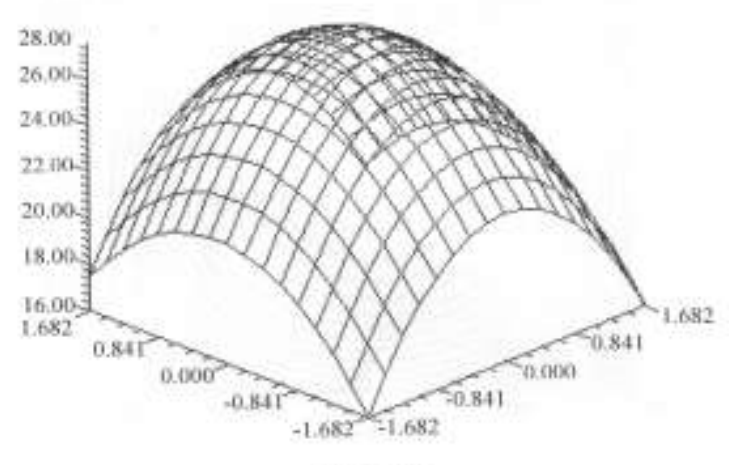

Figure 6.

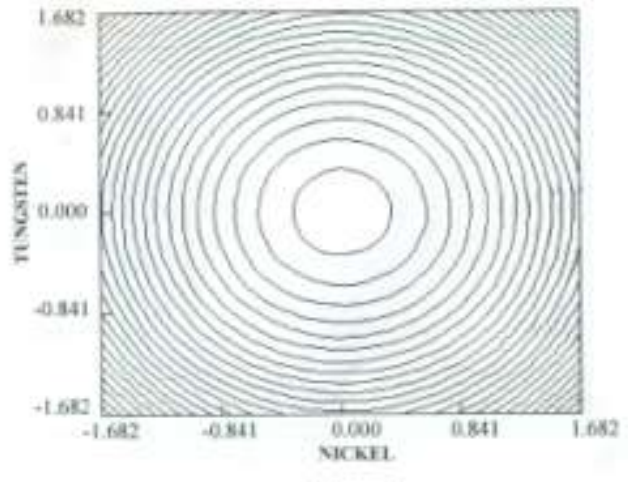

Figure ?.

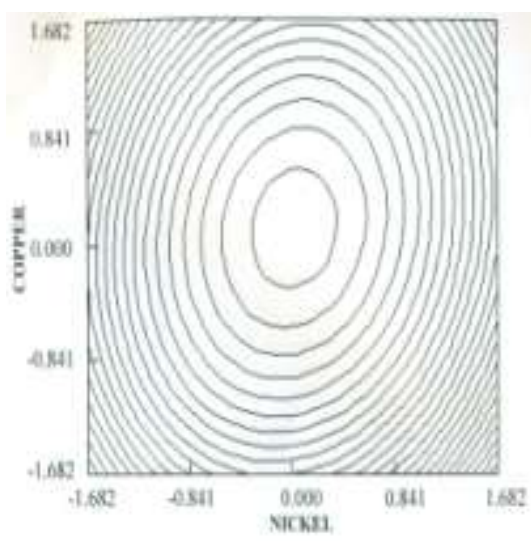

Figure 8.

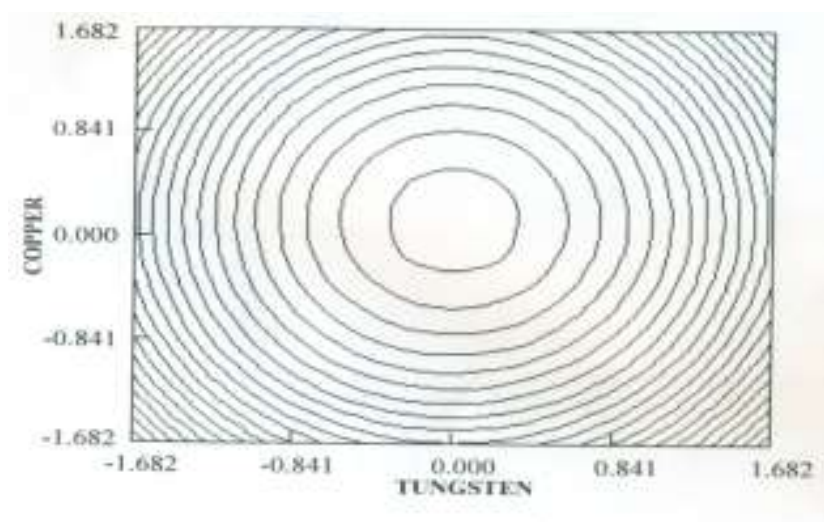

Figure 9. 


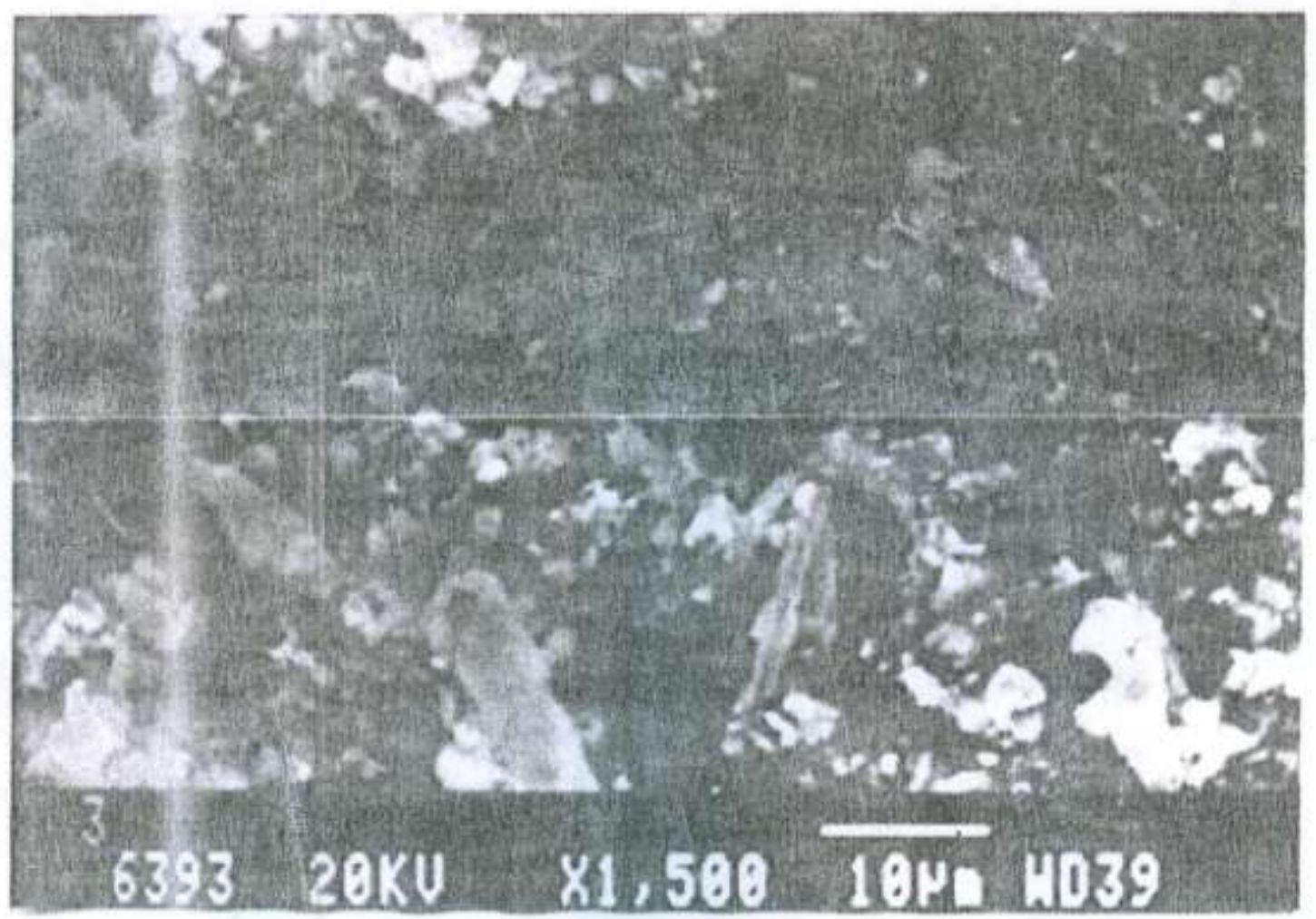

Figure 11a. 


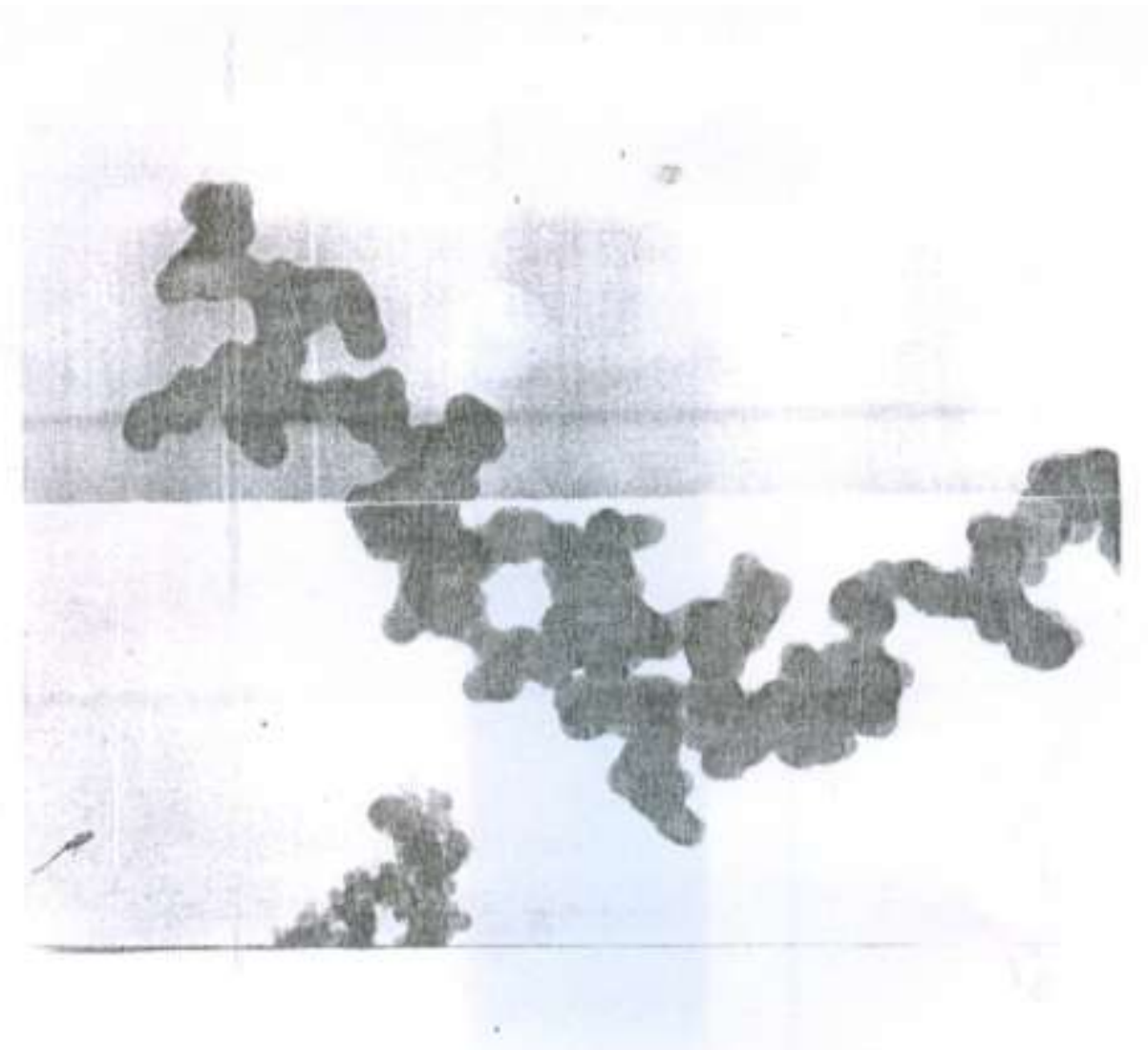

Figure 11b.

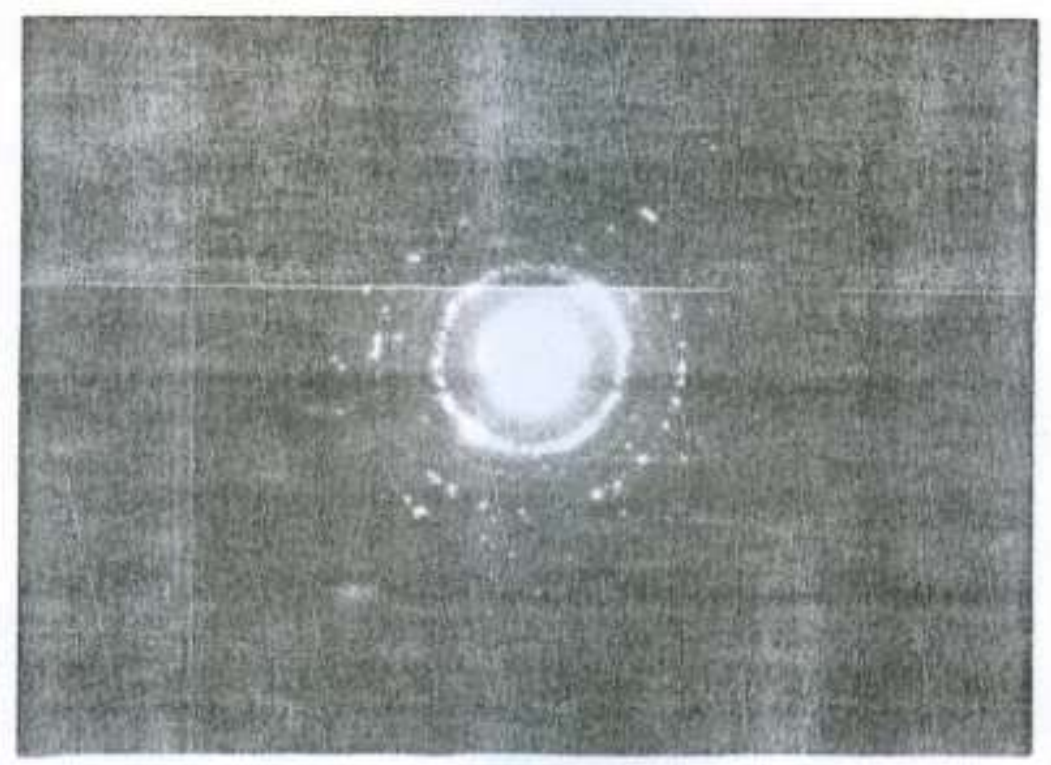

Figure 11c. 


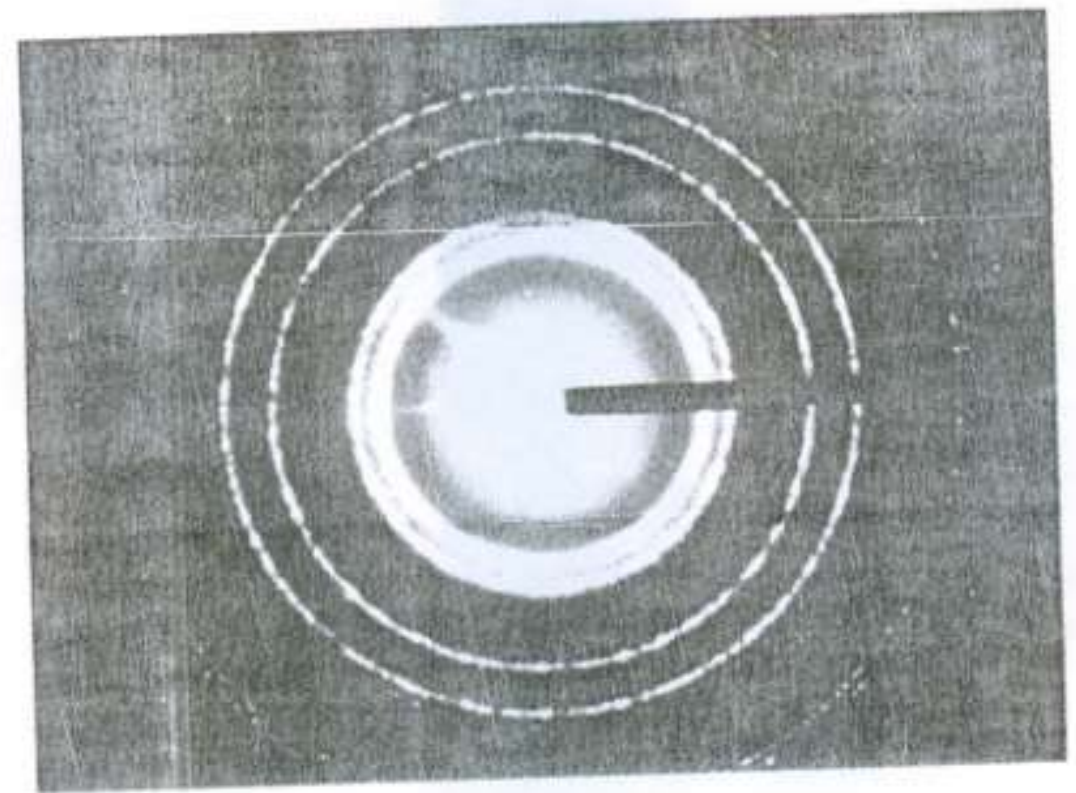

Figure 11d.

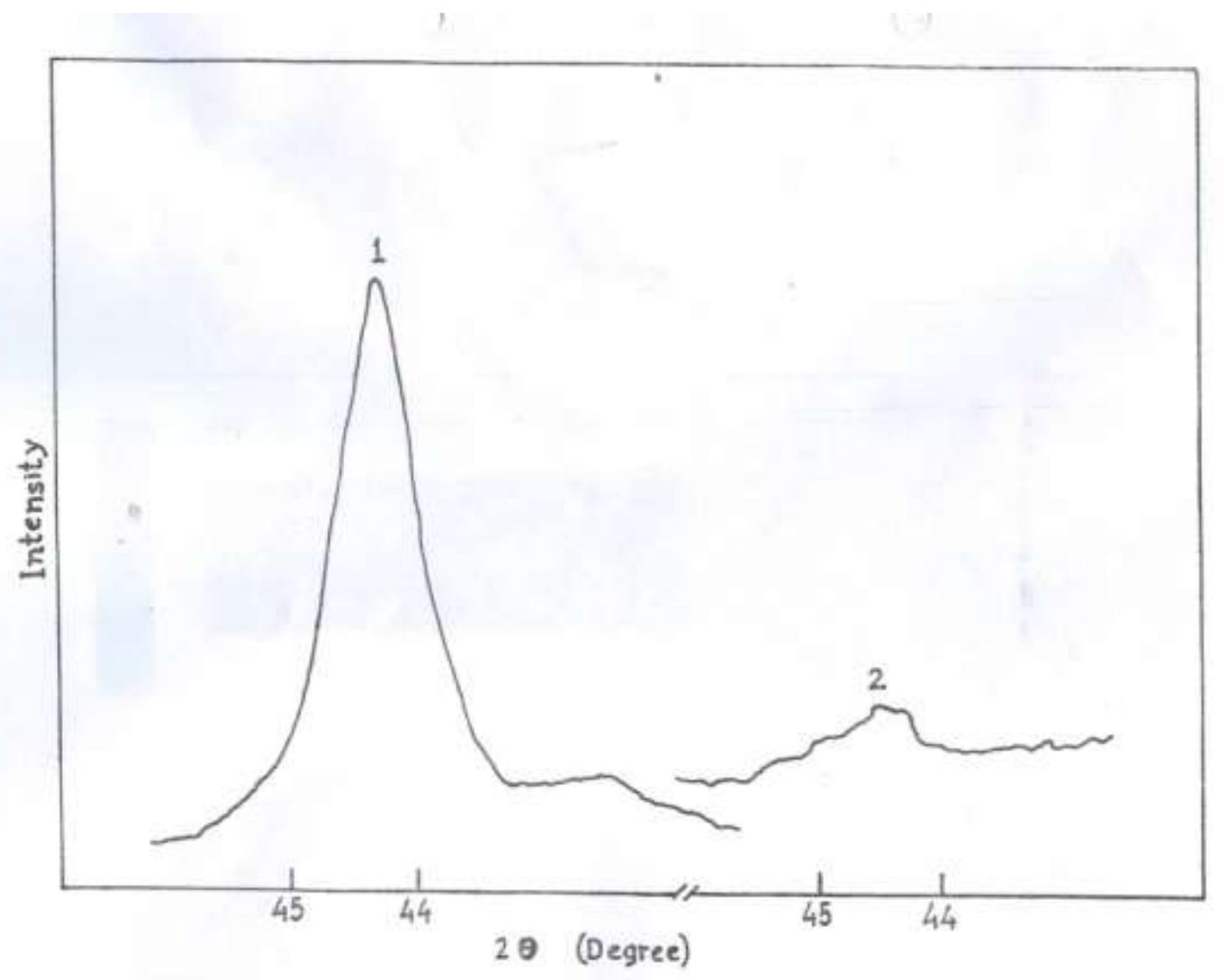

Figure 12 


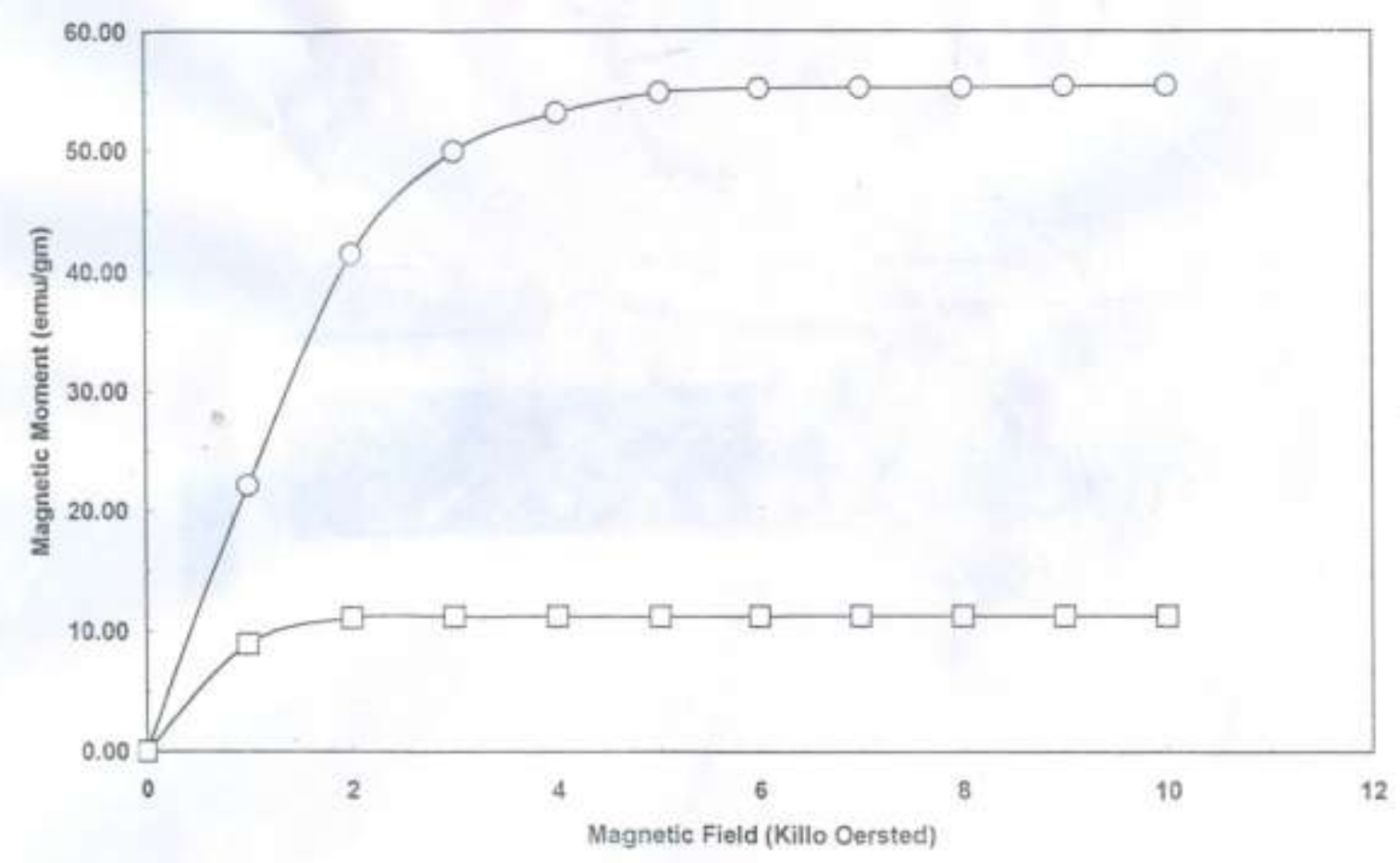

Figure 13, 